\title{
EMIGRACIÓN DE CHINOS DE MACAO A COSTA RICA 1872-1873*
}

\section{EMIGRATION OF CHINESE FROM MACAO TO COSTA RICA 1872-1873}

\author{
Lucy M. Cohen**
}

A Hilda Chen Apuy

\begin{abstract}
RESUMEN
Este artículo presenta un análisis de las políticas sociales y diplomáticas que influyeron en la introducción de trabajadores chinos contratados. Los trabajadores viajaron en el vapor italiano Glensannox de Macao a Costa Rica en 1872-1873. Se examinan las implicaciones de las políticas vigentes a través de las actividades de los agentes de empleo y autoridades gubernamentales en Macao, Hawai y Costa Rica.
\end{abstract}

PALABRAS CLAVE: COSTA RICA * MACAO * CHINOS * TRABAJADORES * AGENTES DE EMPLEO * ABUSOS * POLÍTICA DIPLOMÁTICA

\section{ABSTRACT}

This article presents an analysis of social and diplomatic policies which influenced the introduction of Chinese contract laborers who traveled on the Italian ship Glensannox from Macao to Costa Rica between 1872-1873. Implications of policies are examined through analysis of the activities of labor agents and government authorities in Macao, Hawaii and Costa Rica.

KEY WORDS: COSTA RICA * MACAO * CHINESE * WORKERS * LABOR AGENTS * ABUSES * DIPLOMATIC POLICY

\section{INTRODUCCIÓN}

En su publicación pionera, Emigração de Cules Dossier Macau 1851-1894, Beatriz Basto da Silva señala que, entre enero de 1867 $y$ diciembre de 1872, un total de 212 barcos zarparon de Macao rumbo a Cuba y Perú con trabajadores chinos contratados para realizar

* Traducción del Dr. Fernando Durán Ayanegui.

** Universidad Católica de América, Washington DC. Cohen@cua.edu labores en la agricultura, los ferrocarriles y actividades conexas. Solamente uno de esos barcos, el vapor italiano Glensannox, ocupado por 685 chinos y la correspondiente tripulación, partió con un destino diferente: Costa Rica, en Centroamérica. Basto da Silva describe ese lugar como "destino excepcional""destino único"1.

1 Basto da Silva, Beatriz. Emigração de Cules Dossier Macau 1851-1894. Macau: Fundação Oriente, 1994, p.143. 
El establecimiento de ese grupo de chinos en Costa Rica ha sido documentado por estudiosos cuyo interés se ha centrado en particular, en sus patrones de trabajo, su organización social y sus relaciones inter étnicas en el nuevo país ${ }^{2}$. Los chinos fueron reclutados para trabajar en la agricultura $y$ en el Ferrocarril al Atlántico, que se encontraba entonces en proceso de construcción bajo la responsabilidad de Henry Meiggs Keith.

Sin embargo, las deliberaciones que sobre este asunto tuvieron lugar en el propio territorio de Macao han recibido poca atención. En este artículo me concentraré en las consideraciones políticas que los funcionarios de Macao manifestaron con respecto a los chinos destinados a Costa Rica antes de su partida. Además, las observaciones hechas por la prensa $y$ por las autoridades durante la escala del Glensannox en las islas de Hawai son dignas de interés. En ellas se reflejan, tanto el interés del público como aspectos de interpretación legal que rodearon la emigración de trabajadores contratados desde Macao a Latinoamérica entre 1872 y 1873, poco antes de que el gobierno de Portugal tomase medidas para prohibirla.

Mi interés en la etnohistoria de los chinos del siglo XIX en América es tanto profesional como personal. En años recientes, he estudiado los recursos archivísticos de Macao, Portugal y España, así como de otros sitios

Casey Gaspar, Jeffrey. "El ferrocarril al Atlántico en Costa Rica 1871-1874". Anuario de Estudios Centroamericanos, Primera edición, Ciudad Universitaria Rodrigo Facio, 1976, pp. 291-344. Casey, J. "La inmigración China". En: Revista de Historia, Heredia-Costa Rica, Año I, nro. 1, 1975, pp. 145-165; Fonseca Herrera, Zaida María. "Los chinos en Costa Rica en el Siglo XIX". Tesis de grado, Escuela de Historia y Geografía, Facultad de Ciencias Sociales, Universidad de Costa Rica, 1979; Murillo Chaverri, Carmen. "Identidades de hierro y humo. La construcción del ferrocarril al Atlántico 1870-1890". San José: Editorial Porvenir, 1995. Ver también, Ronald Soto Quirós. "Inmigración e identidad nacional. 1904-1942. Los "otros" reafirman el "nosotros". Tesis para optar por el grado de Licenciatura en Historia. Universidad de Costa Rica: Facultad de Ciencias Sociales, Escuela de Historia, julio 1998, pp. 258-328. relevantes, con el propósito de comprender diversos aspectos de los antecedentes y las imágenes de aquellos chinos enviados desde Macao hacia los confines del Caribe y de la tierra firme americana. En mi condición de nieta de un emigrante chino a El Salvador, me ha llamado la atención por la escasez de investigaciones académicas en torno a los vínculos entre el enclave decimonónico portugués de Macao y los lugares donde se asentaron los trabajadores chinos contratados.

Jeffrey Casey Gaspar y Zaida María Fonseca comentan que la idea de construir un ferrocarril que uniera al Valle Central con la costa atlántica de Costa Rica había sido el sueño dorado del pueblo y de los gobernantes de ese país ${ }^{3}$. Sin embargo, la puesta en práctica del proyecto planteaba retos gigantescos. Dos diferentes contratos para la construcción del ferrocarril, firmados en 1866 y 1869, habían fracasado ${ }^{4}$. En este sentido, Tomás Soley Güell llegó a comentar que el proyecto de construir la vía férrea exigía mucha audacia, ya que los préstamos que deberían gestionarse superaban en mucho los recursos de una población de apenas 150000 habitantes. No obstante, los medios para seguir adelante con el proyecto tenían que ser conseguidos ${ }^{5}$.

A fines de abril de 1870, al convertirse en Presidente de la República, don Tomás Guardia reconoció que el ferrocarril era indispensable para el desarrollo del país. Con el fin de llevarlo adelante escogió a Henry Meiggs, el conocido contratista que había dirigido la construcción de ferrocarriles en Chile y Perú. Meiggs había participado también en un proyecto de construcción de una vía férrea en Bolivia, en 1869, y había explorado la posibilidad de construir el Ferrocarril de Antioquia, en Colombia. Meiggs envió a Costa Rica a su sobrino, Henry

Casey Gaspar. Op. cit., p. 191; Fonseca Herrera, p. 25.

4 Fonseca Herrera, pp. 4-21.

5 Soley Güell, Tomás. Historia Económica y Hacendaria de Costa Rica. Tomo 1, San José: Editorial Universitaria, Sección Ciencias Sociales y Jurídicas, nro. 1, 1947, p. 277. 
Meiggs Keith, para que estudiara la posibilidad de llevar a cabo el proyecto ${ }^{6}$. Como resultado de sus recomendaciones, se firmó, el 20 de junio de 1871, en Lima, Perú, un contrato entre el Gobierno de Costa Rica y don Juan Meiggs, hermano y consejero de Henry Meiggs, en el cuál este último se comprometía a construir el ferrocarril en el corto plazo de tres años, al costo de 1600000 libras esterlinas. El contrato fue aprobado en San José, Costa Rica, el 18 de agosto de 1871, y de inmediato el Presidente Guardia inició las gestiones para obtener los préstamos necesarios ${ }^{7}$.

Uno de los retos que Meiggs Keith debió enfrentar fue el de la escasez de mano de obra, ya que al mismo tiempo había una gran demanda de brazos para las labores agrícolas. El contratista no tardó mucho en darse cuenta de que, si quería terminar el ferrocarril en el plazo de tres años estipulado en el contrato, tendría que importar trabajadores de otras regiones del mundo ${ }^{8}$.

Al principio, trató de conseguir trabajadores blancos, ya que la "Ley de Bases y Colonización" de Costa Rica (Ley 24), que había sido aprobada el 3 de noviembre de 1862, prohibía la colonización del país por parte de personas de raza africana o china, "excepto en casos de necesidad". Sin embargo, dada la escasez de mano de obra para la construcción de ciertos segmentos de la vía, Meiggs Keith hizo planes para introducir inmigrantes, tanto chinos como europeos. Recibió apoyo en vista de que, para entonces, muchos trabajadores chinos contratados habían sido introducidos en

Stewart, Watt. Chinese Bondage in Peru. A History of the Chinese Coolie in Peru, 1849-1874. Durham: Duke University Press, 1951. Stewart, Watt. Keith and Costa Rica. A Biographical Study of Minor Cooper Keith. Albuquerque: The University of New Mexico Press, 1964. Hatch, John Keith. Minor C. Keith Pioneer of the American Tropics. 1962; El Heraldo, Antioquia, Colombia, 1 de abril, 1869, nro. 22 , p. 87.

7 Stewart. Keith and Costa Rica, p. 10-13; Casey Gaspar, 1976, pp. 291-300.

Fonseca Herrera, pp. 25-26; Casey Gaspar, p.17. otras partes de América Latina, en particular en Cuba y en Perú, bajo la creencia de que eran mano de obra barata9 .

El 6 de abril de 1872, Enrique Meiggs Keith y Otto Hübbe y Grytzell, le escribieron al Presidente de Costa Rica para informarle que habían organizado una asociación con el fin de traer al país un total de mil chinos procedentes de Hong Kong o de sitios cercanos. En su carta solicitaban la suma de $\$ 30$ (pesos) por cada chino que fuera reclutado, a manera de compensación por los gastos, haciendo notar que esa práctica compensatoria se había aplicado en Cuba y en Perú. En Costa Rica, la idea de ofrecer subsidios para estimular la inmigración y el establecimiento de colonias europeas, figuraba también en la Ley $24^{10}$.

Meiggs Keith y sus asociados sugirieron que el gobierno nombrara una comisión encargada de supervisar el trato que darían a los chinos las personas que los contrataran. Para asegurar el éxito de la empresa propuesta, el 10 de abril de 1872 el señor Hübbe fue designado "Agente de Gobierno de Costa Rica para la contratación de trabajadores chinos"11.

La autorización final fue aprobada por el Secretario de Obras Públicas, en los términos descritos, el 12 de abril de 1872 y quedó establecido que el título de "Agente del Gobierno" sólo podía ser usado por el señor Hübbe ante las autoridades $y$ en relación con los chinos ${ }^{12}$. Otto Ibid.

10 Cartas a Su Excelencia el Presidente de la República, de Enrique M. Keith, Hübbe, y Grytzell, San José, 6 de abril de 1872 y 10 de abril de 1872. En: Archivo Nacional de Costa Rica, Sección Histórica, Secretaría de Fomento, Nro. 1055, citado en: Casey Gaspar, Jeffrey, "La inmigración China". En: Sección Documental, Revista de Historia, Universidad Nacional, Escuela de Historia, Heredia, Año I, Nro. I, 1975, pp. 147-149.

11 Ibíd., 10 de abril de 1872

12 Carta del Secretario de Estado en el Despacho de Obras Públicas, San José, abril 12, 1872, en relación con la solicitud de los señores Henry Meiggs Keith y Hübbe and Grytzell. En: Casey Gaspar, Jeffrey. "La inmigración china”. op. cit., pp. 151-152. 
Hübbe había tenido ya experiencia en el reclutamiento de trabajadores chinos en Hong Kong ${ }^{13}$.

\section{MACAO COMO CENTRO DE RECLUTAMIENTO DE CHINOS EMIGRANTES}

Lo más probable es que Hübbe haya tomado la decisión de reclutar los trabajadores en Macao porque sabía que, desde 1850, de ahí había salido el mayor número de chinos contratados para trabajar en América Latina, en especial en Cuba y Perú. Estos trabajadores eran usualmente reclutados por agentes extranjeros, españoles o peruanos, mediante la ayuda de intermediarios chinos que recorrían los territorios cercanos en busca de posibles candidatos

Otto Jonathan Hübbe Berqueest, nacido en Hamburgo, Alemania (26 de abril de 1842), establecido en Costa Rica a fines de la década de 1850 o a principios de la de 1860, probablemente gracias a sus contactos con la empresa de Johan Knöhr e Hijos, considerada una de las más poderosas casas comerciales de Costa Rica en aquella época. Hübbe fue activo en la promoción de proyectos agrícolas y de colonización, así como de iniciativas comerciales en Costa Rica. En abril de 1872, se unió a Henry Meiggs, E. Grytzell, Guillermo Nanne $y$ Eusebio Figueroa en una petición para desarrollar un proyecto de colonización en la región de Salamanca (ver Carmen Murillo Chaverri. Op. cit., pp. 65 y 72-101). Aquel mismo mes solicitó al gobierno de Costa Rica que lo comisionara para reclutar trabajadores chinos en Macao para la agricultura y para la construcción del ferrocarril al Atlántico. Ver, Eugenio Herrera Balharry. Los alemanes y el Estado Cafetalero. San José: Editorial Universidad Estatal a Distancia, 1988; Werner F. Leopold. "Der Deutsche in Costa Rica". N.p., 196, pp. 67-68. Archivo Nacional de Costa Rica, Judicial, San José, Juzgado Segundo Civil 9420. Agradezco la ayuda de la Dra. María Eugenia Bozzoli en la búsqueda de datos sobre las fechas de nacimiento $y$ muerte del Sr. Hübbe.

Para información sobre las subsecuentes actividades de Hübbe en Costa Rica y en Alemania, ver: Margarita Torres y Gertrud Peters. "Expropiación de la finca cafetalera La Caja en Costa Rica en el entorno de la Segunda Guerra Mundial". Artículo inédito, 2007. Nota: El Sr. Hubbe falleció en Bramfeld, Distrito de Starmann, Alemania, el 15 de junio de 1910. para el trabajo en países de ultramar; estos eran trasladados a Macao, donde los agentes y sus empleados les brindaban alojamiento temporal mientras completaban los trámites de salida de acuerdo con las regulaciones gubernamentales, las cuales estaban diseñadas para garantizar que la decisión de los trabajadores, de irse a trabajar en el extranjero, fuera voluntaria. Cada trabajador se comprometía a firmar un contrato de trabajo de ocho años de duración. Aquellos que no desearan emigrar eran devueltos a sus lugares de origen. Los funcionarios debían asegurarse de que cada trabajador comprendiera los términos del contrato que iba a firmar, mientras que el Capitán del Puerto tenía que hacer la inspección del barco necesaria para garantizar que estaba equipado de manera apropiada para el largo viaje hasta el puerto de destino.

Más aún, antes del zarpe, el capitán de cada embarcación tenía que hacer un depósito de mil patacas en garantía de que se seguirían las reglas establecidas para el buen funcionamiento de los barcos y el correcto cuidado de los pasajeros. El depósito era devuelto una vez que el cónsul destacado en el país de destino informara a las autoridades de Macao sobre el arribo del barco con la totalidad de sus ocupantes. Este informe debía llegar a Macao en un plazo no mayor de 18 meses contados a partir del zarpe y era publicado en el Boletim do Governo de Macau, el periódico oficial del gobierno de $\mathrm{Macao}^{14}$.

\section{CONTRATACIÓN DE LOS \\ TRABAJADORES CHINOS EN MACAO}

Aun cuando la presencia de Hübbe en Macao y Hong Kong fue observada desde

14 Ver, Basto da Silva, Beatriz. Op. cit., 33-34; Teixeira, Manuel. "O Comércio de Escravos em Macau The So Called Portuguese Slave Trade in Macao". Macau: Imprensa Nacional, 1976; de Castro Sampaio, Manuel. "Os Chinos em Macau". Hong Kong: Typographia de Noronha e Filhos, 1867; Montalto de Jesus, C.A. Macau Histórico. Livros do Oriente, Macau, 1990 (Traducido del inglés original, 1926, por Maria Alice Morais Jorge), pp. 271-277. 
principios de octubre de 1872, el anuncio oficial de sus actividades de reclutamiento ocurrió el 12 de noviembre del mismo año, cuando el Gobernador de Macao, Januário Correia de Almeida, Vizconde de San Januário, se dirigió a Su Excelencia, el Ministro de Relaciones Exteriores de Portugal, para informarle que el señor Otto J. Hübbe, Comisionado del Gobierno de Costa Rica, había llegado a Macao para solicitar la aprobación de un intento dirigido a reclutar colonos chinos que serían dedicados, por el gobierno del país centroamericano, a labores agrícolas ${ }^{15}$. El Gobernador indicaba en su informe que, si bien él no sabía nada sobre la naturaleza de la designación del señor Hübbe como Comisionado del Gobierno de Costa Rica, este había entregado un documento oficial mediante el cual el gobierno costarricense garantizaba que emplearía a los trabajadores chinos y cuidaría apropiadamente de ellos y que, por otra parte, las credenciales del petente incluían documentos del Ministerio de Relaciones Exteriores de Costa Rica, confirmados por el Ministro Residente de Estados Unidos y por su Departamento de Estado. El Gobernador San Januário mencionaba que tales documentos se encontraban debidamente archivados en su oficina. El Gobernador informaba, además, que en vista de que el señor Hübbe se mostraba dispuesto a cumplir con las condiciones establecidas en las regulaciones vigentes, él le había extendido la autorización para reclutar colonos chinos que deberían partir del puerto de

Januário Correia de Almeida (1829-1901) fue gobernador de la Provincia de Macao y Timor entre 1872 y 1874 . Era graduado en matemáticas de la Universidad de Coimbra, 1853. Sirvió en Cabo Verde como Director de Obras Públicas y, en 1860-1861, como Gobernador interino de las Islas. Después de servir como Gobernador de la India (1870-1871), en 1872 fue nombrado Gobernador de Macao y Timor. Mientras ocupó ese cargo, visitó Japón como Ministro Plenipotenciario de Portugal ante China, Japón y Siam. Regresó a Lisboa en 1875. Para una biografía detallada, ver P. Manuel Teixeira. "Visconde de S. Januário". En: A Medicina em Macau, Vol. I, Macau: Imprensa Nacional, 1976, pp. 79-99.
Macao hacia el destino propuesto, Costa Rica ${ }^{16}$. Adicionalmente, el Gobernador destacaba el hecho de que aquel permiso se concedería por una sola vez, dado que Portugal y Costa Rica no tenían relaciones diplomáticas. Una vez que ambos países aprobaran un tratado conjunto de comercio y amistad, lo mismo que el intercambio de autoridades consulares, podrían tener lugar otros reclutamientos ${ }^{17}$.

Un aspecto al que el Gobernador, como era su deber, le prestó especial atención, fue el plan para la protección de los chinos en su país de destino. El Gobernador señalaba que los colonos reclutados serían protegidos desde su arribo a Costa Rica, en condiciones equivalentes a las que se ofrecían en Cuba y Perú ${ }^{18}$. Los chinos enviados a Cuba y Perú desde Macao quedaban bajo la protección de Portugal, y los cónsules portugueses en esos dos países tenían la responsabilidad de enviar confirmaciones escritas de la llegada de los barcos y de los pasajeros procedentes de Macao ${ }^{19}$. En vista de que no había, en Costa Rica ni en ningún otro país centroamericano, funcionarios diplomáticos o consulares de Portugal, el plan era hacer que el transporte de los trabajadores tuviera lugar en un vapor italiano y fuera el Cónsul de Italia en Costa Rica quien supervisara su llegada a Costa Rica y se ocupara de su bienestar. El Cónsul de Italia en Macao, el Barón de Cercal, aprobó dicho procedimiento ${ }^{20}$.

16 Carta del Gobernador de la Provincia, Vizconde de San Januário a Su Excelencia el Ministro y Secretario de la Marina y de Asuntos Exteriores, Macao, 12 de noviembre de 1872, en Arquivo Histórico Ultramarino, Lisboa, Caixa 43, nro. 208, 1872.

$17 \quad$ Ibid.

$18 \quad$ Ibid

19 Basto da Silva, Beatriz, pp. 33-34.

20 Antonio Alexandrino de Melo (1837-1885) recibió el nombre de segundo Barón de Cercal el 16 de septiembre de 1863. Aunque nacido en Macao, recibió su educación en la escuela jesuita de Stonyhurst, Sussex, Inglaterra, en Francia y en Roma. Ingeniero de profesión, hablaba francés, inglés y español, lo mismo que chino. Era el propietario de cinco navíos que conectaban 
El Gobernador concluyó su informe declarando que, antes de su partida, los colonos recibieron explicaciones claras sobre el país al que estaban destinados, y que el Cónsul de Italia en Macao también los había visitado. Puso énfasis en el hecho de que el Superintendente de la Emigración China había tomado todas las precauciones necesarias para garantizar que cada uno de ellos se embarcaba voluntariamente.

Hizo notar que, dado que siempre había un intercambio de productos entre Macao $y$ los países adonde emigraban los colonos chinos, parecía recomendable que en el futuro se negociara con Costa Rica un tratado similar al que había sido firmado recientemente entre China y Perú. De ese modo, se fortalecerían las relaciones mutuas, se podrían autorizar nuevas emigraciones y sería posible establecer un intercambio de productos entre ambos países. (Nota: el Virrey Li Hung Chan, de China, y el Capitán Aurelio García y García, de Perú, designado como Enviado Extraordinario y Ministro Plenipotenciario ante los gobiernos de China y de Japón, firmaron un tratado de amistad, comercio y navegación, lo mismo que una convención sobre migración, el 26 de junio de 1874).

Tras la autorización oficial para el reclutamiento de chinos, el señor Hübbe escogió un agente laboral, Nicolás Tanco Armero, quien tenía gran experiencia en la contratación de chinos para que fueran a trabajar en el continente americano. Tanco era nativo de Bogotá, Colombia, con conexiones de parentesco en Cuba. Se había establecido en 1853, como exiliado político, en La Habana, donde fue primero

regularmente Portugal, Brasil y Australia. Era uno de los más acaudalados hombres de Macao, a pesar de las cuantiosas pérdidas sufridas con el desarrollo de Hong Kong. Desempeñó varias posiciones consulares, entre ellas la de Cónsul de Italia en Macao, designado en 1869, Vicecónsul de Francia en Macao, designado en 1872, Cónsul de Brasil desde 1875 y Cónsul de Bélgica desde 1876. Como ingeniero, diseñó varios edificios en Macao (ver "Alexandrino Antonio de Melo". En: Jorge Forjaz. Familias Macaenses. Vol. II. Fundação Oriente, Instituto Cultural de Macao, Instituto Portugués del Oriente, Macao, 1996, pp. 646-657). profesor de matemáticas $y$, subsecuentemente, empleado del ferrocarril. En 1855, residiendo todavía en la Isla, Tanco Armero fue empleado por los hacendados cubanos J.M. Morales y Joaquín Pedroso para que viajara a China a reclutar trabajadores para sus plantaciones de caña de azúcar ${ }^{21}$. En tal carácter, Tanco Armero se convirtió en uno de los principales agentes de la emigración China hacia Cuba y Perú en las décadas de 1850, 1860 y 1870. Su libro Viaje de Nueva Granada a China y de China a Francia, fue uno de los más conocidos relatos escritos por un latinoamericano sobre un viaje a China en el siglo XIX ${ }^{22}$.

Cuando el señor Hübbe llegó a Macao, Tanco Armero tenía contratado el vapor italiano Glensannox para el envío de trabajadores chinos al Callao, Perú. Como respuesta a una solicitud del señor Hübbe, Tanco Armero decidió cambiar el destino del vapor de Callao al puerto costarricense de Puntarenas. Aunque este cambio de destino creó alguna confusión entre los funcionarios gubernamentales, el asunto fue aclarado según lo indican los siguientes intercambios ${ }^{23}$.

El 21 de octubre de 1872, Henrique de Castro, Secretario General del Gobierno de Macao, le escribió a João Eduardo Scarnichia, Capitán del Puerto de Macao, en relación con el destino del vapor italiano Glensannox. De Castro citaba un reporte de inspección que el mismo Capitán del Puerto había proporcionado

21 "Emigración China de Macao para la Habana". Archivo Histórico Nacional, Madrid, Sección Ultramar, Legajo 86, Carpeta 4, Expediente 38; Ver también, Juan Pérez de la Riva. El Barracón y Otros Ensayos. La Habana: Editorial de Ciencias Sociales, Instituto Cubano del Libro, 1975.

22 Nicolás Tanco Armero. Viaje de Nueva Granada a China y de China a Francia (con una Introducción por Pedro María Moure). París: Imprenta de Simon Raçon y Comp., 1861.

23 Carta a su Excelencia Henrique de Castro, secretario General del Gobierno, de João E. Scarnichia, Capitán del Puerto, 19 de octubre de 1872. Lisboa Arquivo Geral da Marinha, Nucleo 916, Caixa 4, Correspondencia Recebida e expedida desde 4-11871 a $20-3-1875$, pp. 90-91. 
para este vapor el 19 de octubre de 1872 , con la declaración de que su destino era el Callao, Perú. Este reporte incluía información sobre un certificado extendido por el Jefe de Sanidad Pública, según el cual al vapor se le permitiría transportar hasta aquel puerto un máximo de 739 colonos $^{24}$. De Castro señaló que el Gobernador necesitaba una aclaración: ¿había, el agente Armero, cambiado de planes? Es decir, ¿planeaba enviar el Glensannox a Perú o a Costa Rica? "Si el vapor tiene como destino Costa Rica, el Capitán del Puerto debe declarar a cuál puerto de Costa Rica se dirigirá la nave". Además, preguntaba "si acostaría en la costa del Pacífico o en la costa atlántica"25.

En respuesta, el Capitán Scarnichia aclaró las causas de la confusión mediante la cita de la correspondencia cursada entre los funcionarios del caso. Primero, el 22 de octubre de 1872 dio respuesta a la carta escrita por orden de Su Excelencia el Gobernador, indicando que el destino de Callao, Lima, mencionado en la correspondencia oficial, se encontraba en conformidad con la entrada que figuraba en libro del Departamento ${ }^{26}$.

A la carta del 22 de octubre siguió otra, de fecha 23 de octubre, firmada por el Capitán Scarnichia y dirigida a Su Excelencia Señor H. De Castro. En esta nota, el Capitán Scarnichia contesta que "en respuesta a la segunda parte de su mensaje, en el que Su Excelencia deseaba saber a cuál puerto de Costa Rica se dirigiría el Glensannox en su próximo viaje y si este puerto

Ibíd.

Carta de Henrique de Castro, Secretario General del Gobierno, a Su Excelencia el Capitán del Puerto, 21 de octubre de 1872, Lisboa: Arquivo Histórico de Macau, Marinha, 1872, Repartição dos Servicios de Educação, Nucleo 916, Caixa 4, Processo 1872, nro. 758, Secretaria do Governo de Macau e Timor.

Carta a Su Excelencia Henrique de Castro, Secretario General de Gobierno, de João E. Scarnichia, Capitán del Puerto, Lisboa, Arquivo Geral da Marinha, octubre 22, 1872, Nucleo 916, Capitania do Porto de Macau, Caixa 4, Oficios Expedidos Desde 4-1871 a 20-3-1873. está situado en la costa del Pacífico o en la costa atlántica", informa que el puerto de destino se llama "Ponta de Arenas" y está localizado en la costa del Pacífico, a treinta y cinco millas de San José, la capital del país ${ }^{27}$. Posteriormente fue más detallado con respecto a este plan en la carta que, con fecha 2 de noviembre de 1872, le escribió al Secretario General del Gobierno de Macao, en la que le informa que el vapor italiano Glensannox, consignado a don Nicolás Tanco Armero, Agente de Emigración China, había entrado en la región de Macao el día anterior, procedente de Vampu (Whampoa) y debería dirigirse luego hacia el puerto de "Ponta da Arena”, en Costa Rica ${ }^{28}$.

H.A. Pereira Rodrigues, Superintendente de Emigración China en Macao, le informó al Capitán Scarnichia, en carta del 6 de noviembre de 1872, en relación con las órdenes que el Gobierno había dado el día 5 del mismo mes, que ya había sido admitida la petición de don Nicolás Tanco Armero, y agregó algunas especificidades sobre el local en el que había alojado a los colonos antes de la partida hacia Costa Rica ${ }^{29}$. El 8 de noviembre de 1872 , H.A. Pereira Rodrigues le escribió de nuevo al Capitán Scarnichia para informarle que los colonos chinos destinados al vapor italiano

Carta a Su Excelencia Henrique de Castro, Secretario General del Governo, de João Scarnichia, Capitán del Puerto de Macao, 23 de octubre de 1872, en Lisboa, Arquivo Geral da Marinha, Capitania do Porto de Macau, Nucleo 916, Caixa 4, Capitania do Porto de Macau, Oficios Expedidos.

28 Carta a Su Excelencia Henrique de Castro, Secretario General del Governo, de João E. Scarnichia, Capitán del Puerto, 2 de noviembre de 1872, Lisboa, Arquivo Geral da Marinha, Nucleo 916, Caixa 4, p. 91, Oficios Expedidos desde 4-11871 a $20-3-1873$.

Carta de H.A. Pereira Rodrigues, Superintendente de Emigración China, a João Scarnichia, Capitán del Puerto, 6 de noviembre de 1872, Lisboa, Arquivo Geral da Marinha, Caixa 4, Correspondencia Recebida /Expedida, 1870-1872, Nucleo 916, Caixa 4, En Fólder 1872, nro. 443. 
deberían abordar el siguiente día y solicitó la orden formal de embarque ${ }^{30}$.

Una vez conocidos los planes de partida, el 12 de noviembre el diario The Hong Kong Daily Press, que había sido crítico de la emigración extraordinaria de coolíes chinos a Costa Rica porque este país no tenía relaciones con Portugal ni con China, informó que la migración de Macao a Costa Rica era "un fait accompli", y que los coolíes "estarían bajo la protección del Consulado de Italia en Cartago, la capital de Costa Rica"31.

Días después, concretamente el 16 de noviembre, el Secretario General Henrique de Castro recibió una carta del Capitán Scarnichia en la que le informaba que él había realizado la inspección final. De hecho, ese mismo día el vapor italiano levó anclas en Macao con destino a "Ponta de Arena" en Costa Rica, con una total de 685 colonos chinos que contaban con contratos y partían voluntariamente. El vapor pesaba 1251 toneladas y el Capitán era D. Capello, quien declaró no haber encontrado evidencia de que entre los colonos hubiera algún pirata. Como se requería, un médico y un intérprete formaban parte de la tripulación ${ }^{32}$.

De aquel modo, el señor Hübbe completó su misión de enviar a Costa Rica los trabajadores chinos contratados, $y$ los registros oficiales de Macao sugieren que fue el Gobernador San Januário quien encontró la solución diplomática que le permitiera autorizar aquel reclutamiento destinado al poco conocido país de Costa Rica.

30 Carta de H.A. Pereira Rodrigues, Superintendente de Emigración China, a João Eduardo Scarnichia, Capitán del Puerto, 8 de noviembre de 1872, Lisboa, Arquivo Geral da Marinha, Nucleo 916, Superintendencia de Emigração Chineza, Correspondencia Recebida, Caixa 4, nro. 447.

31 Hong Kong Daily Press, 12 de noviembre de 1872, nro. 4683, p. 2.

Carta de João E. Scarnichia, Capitán del Puerto, a Su Excelencia Henrique de Castro, Secretario General del Gobierno, 16 de noviembre de 1872 , Lisboa, Arquivo Geral da Marinha, Nucleo 916, Caixa 4, Correspondencia Recebida e Expedida, 1870-1872. Ver también, Boletim da Provincia de Macau e Timor. 23 de noviembre, 1872, XVIII, nro. 48, p. 206.
Normalmente, los trabajadores chinos contratados para trabajar en Cuba y Perú viajaban con documentos portugueses, ya que China no tenía relaciones consulares con aquellos territorios. Una vez llegados a su destino, el Cónsul portugués en cada localidad debía confirmar la llegada del barco. Este mismo Cónsul debía proteger los intereses de los chinos mientras estos residieran en su jurisdicción. Sin embargo, al no haber en aquel momento funcionarios consulares o diplomáticos portugueses en Costa Rica ni en ningún otro país de Centroamérica, el Gobernador, en consulta con el Cónsul de Italia en Macao, el Barón de Cercal, aprobó el plan de enviar a los chinos destinados a Costa Rica en un barco italiano, en el entendido de que el Cónsul de Italia en Costa Rica los recibiría a su llegada y continuaría actuando como su protector.

\section{EL GLENSANNOX HACE ESCALA EN HONOLULU, HAWAI}

En su ruta hacia Costa Rica, el Glensannox hizo escala en Honolulu, Hawai. El 21 de diciembre de 1872, el periódico de Honolulu Pacific Commercial Advertiser informaba del arribo, el día anterior, del vapor italiano, capitaneado por Domenico Capello, tras 33 días de navegación desde $\mathrm{Macao}^{33}$. Se indicaba, además, que la nave iba "In transitu hacia Punta Arenas con 105 tons. de mercancía y Efectos Personales, (y) 685 Chinos," y que "Para promover la salud y comodidad de los Chinos, el Capitan y oficiales concluyeron que harían escala aquí para obtener provisiones frescas, agua y carbon, $y$ así lo han hecho"34.

De hecho, pocas semanas antes de la llegada del barco ya se había comentado en la prensa hawaiana el plan de llevar trabajadores chinos a Costa Rica. El 30 de noviembre, el Pacific Commercial Advertiser citaba en un editorial el artículo, "Immigration for Costa Rica" aparecido en un reciente número del Panama

Pacific Commercial Advertiser, Honolulu, 21 de diciembre de 1872 , nro. 865 , XVII, nro. 25 , p. 2. diciembre de 1872, nro. 866, XVIII, Nro. 26, p. 2. 
Star and Herald, y en el periódico costarricense El Ferrocarril (15 de noviembre de 1872). El autor comentaba que Costa Rica estaba

... asumiendo rápidamente un lugar modelo entre la mayoría de las repúblicas latinoamericanas. Para obtener $y$ mantener esta superioridad la nacion debe aumentar su población y no dejar su industria, [y después de discurrir un tanto sobre los modelos de inmigración de Estados Unidos, concluía]: La experiencia y la publicidad están estrechamente unidas y aunque no dudamos que el plan de introducir coolíes aliviará considerablemente las presiones laborales, no debemos de perder de vista la adquisición de inmigrantes industriosos y saludables y de la raza Caucasiana ${ }^{35}$.

Tras el arribo al Hawai, el Capitán del Glensannox obtuvo los necesarios alimentos frescos y otros abastecimientos. Hacia el final de la escala, el 26 de diciembre, la prensa local informó de un recurso de habeas corpus presentado ante la Corte Suprema de Hawai, presidida por el Juez J. Hartwell. Una orden de habeas corpus se procesó de la Corte Suprema, por petición de "tres poco conocidos residentes Chinos" de Honolulu por virtud del hecho que tres de los coolies Chinos a bordo del Glensannox se quejaron de haber sido ilegalmente detenidos por el capitán del barco y privados de libertad. Estos tres chinos habían bajado a tierra y uno de ellos había decidido no continuar el viaje hacia Costa Rica. Los otros dos habían retornado al barco ${ }^{36}$.

En el Recurso de habeas corpus presentado en nombre de Wong Sou et ál., detenidos a bordo del vapor italiano Glensannox, "el petitorio alegaba tratamiento cruel y retención ilegal de Wong Sou y otros dos chinos a bordo del

35 "Immigration for Costa Rica", Pacific Commercial Advertiser, Honolulu, 30 de noviembre de 1872 , nro. 862 , XVII, nro. 22, p. 5.

Pacific Commercial Advertiser, 28 de diciembre de 1872, nro. 866, XVIII, nro. 26, p. 2. mencionado barco"37. Los chinos que habían bajado de la nave fueron, a su vez, acusados de romper el contrato al descender a tierra. Las quejas de los chinos fueron refutadas por el Capitán indicando que "él solo exigía el orden $y$ la disciplina requeridos para la seguridad $y$ comodidad de todos a bordo"38.

En su examen del caso, el Juez Hartwell consideró dos cuestiones: la naturaleza de la autoridad del capitán y el carácter obligante de un contrato suscrito en territorio extranjero. En cuanto a "si un chino podía ser detenido a bordo de un barco en el puerto de Honolulu y mantenido ahí contra su voluntad bajo custodia del capitán", el Juez Hartwell comentó:

... El Capitán de un barco es como un emperador a bordo. [...] En el caso de este pasajero es innecesario decidir si se incurrió en crueldad o severidad no autorizada, sino únicamente si por la autoridad del capitán a él se le podía impedir que descendiera a tierra. Diré, por lo tanto, que no estoy convencido de que a bordo del barco se hayan tomado medidas más estrictas que lo que se requería para mantener el buen orden... ${ }^{39}$.

En cuanto a la naturaleza del contrato laboral, el Juez Hartwell señaló:

... Este no es un caso de amo y sirviente, pero si lo fuera nuestras leyes relativas a este tema no se aplicarían porque este es un contrato ejecutable en el extranjero y no aquí, como lo requiere nuestra legislación... Es un contrato para servir durante ocho años, $y$ no durante cinco como lo requiere nuestra ley; es un contrato asignable, que nuestra ley declara expresamente que es nulo e inválido en el aspecto penal. De nuevo, este contrato establece que el sirviente no abandonará

37 "Supreme Court, Before Hartwell, J., at Chambers". 27 de diciembre de 1872, citado en: Hawaiian Gazette, 1 de enero de 1873, VIII, nro. 51, p. 3. 
la propiedad del patrono sin un permiso escrito. Nuestra legislación les permite a los sirvientes moverse libremente para ir a plantear su queja ante cualquier magistrado habilitado para escucharlos. $\mathrm{Y}$, finalmente, de acuerdo con sus términos, no se encuentra aún en vigencia, ya que el servicio acordado en él solamente comenzará cuando el grupo llegue a su puerto de destino... ${ }^{40}$.

El Juez Hartwell concluyó su argumento afirmando:

No veo, en el contrato ni en nuestras leyes o tratados, autoridad mediante la cual el capitán pueda impedirle a este pasajero tocar tierra, o autorice a esta Corte a ordenarle que permanezca a bordo. De acuerdo con la ley, él puede poner pie en estas costas tan libremente como podría hacerlo cualquier otro pasajero, $y$ en consecuencia se le deja en libertad... ${ }^{41}$.

La decisión del Juez Hartwell, que fortaleció la autoridad del capitán a bordo, tocó también aspectos relativos a la naturaleza del contrato laboral. Las leyes hawaianas aplicables eran diferentes en cuanto a la duración del servicio y a ciertos aspectos de la libertad de movimiento. Sin embargo, un aspecto crucial en la decisión del juez fue el hecho de que el contrato no era obligante antes de que las partes llegaran a su puerto de destino.

Hacia el final de la escala de una semana de duración, un columnista del Pacific Commercial Advertiser escribió algunos comentarios sobre los chinos, que aparecieron en el Hawaiian Gazette. El Advertiser refutó los reportes del Hawaiian Gazette, según los cuales el gobierno italiano permitía el uso de su bandera para ocultar el tráfico de esclavos, informando que los agentes de hacendados de Costa Rica habían ido a Macao a contratar cierto número de trabajadores chinos para trabajar en las

$\begin{array}{ll}40 & \text { Ibíd. } \\ 41 & \text { Ibíd. }\end{array}$

plantaciones de café y azúcar en aquel país centroamericano, y que la compañía naviera que los transportaba poseía una buena clase de vapores adecuados para aquella función. Agregó que, bajo la bandera de Italia, el Cónsul de ese país europeo en Macao había examinado y firmado cada contrato individual antes de permitir que el barco recibiera a los chinos, $y$ una vez que el Glensannox estuvo listo para zarpar subió a bordo para preguntarle a cada uno de ellos, en forma individual, si partía voluntariamente. A dos de ellos que se echaron atrás se les permitió abandonar la nave antes de que el Glensannox reiniciara su viaje ${ }^{42}$.

El 27 de diciembre de 1872, antes de la partida, el Capitán Capello recibió a cierto número de invitados a bordo del Glensannox. En el barco los visitantes fueron informados de que el vapor italiano era uno de seis navíos similares que pertenecían a una empresa dedicada al transporte de coolíes desde "Macao a Centroamérica" 43 . El vapor fue descrito como una embarcación buena y espaciosa, de 2000 toneladas de capacidad, con condiciones adecuadas para la actividad a la que estaba destinada. Los coolíes parecían estar "bien alimentados y saludables". El Pacific Commercial Advertiser finalizaba su reportaje sobre la visita anotando que los invitados habían inspeccionado "todo el barco" y se habían mostrado complacidos con la forma como habían sido acomodados los chinos para su viaje a Costa Rica. Las cubiertas eran limpias y ventiladas y los ocupantes de las largas filas de tarimas "se veían bien alimentados y saludables". El reportero escribió que "mucho dudamos que existan mejores disposiciones sanitarias y de orden en cualquier buque militar con el mismo número de hombres a bordo" ${ }^{44}$.

Cuando el Glensannox partió rumbo a "Punta Arenas", el 28 de diciembre de 1872, su lista de aprovisionamientos adquiridos en

42 Pacific Commercial Advertiser, 28 de diciembre de 1872, nro. 26, nro. 866, XVIII, p. 2.

Ibíd., p. 3.

$44 \quad$ Ibid. 
Honolulu para la atención de los pasajeros y la tripulación ${ }^{45}$ constaba de:

Cabezas de ganado .................5

Pollos ......................... 200

Toneladas de carbón ............... 200

Limas........................... 2000

Naranjas..................... 4000

Calabazas.................... 300

Libras de camote............... 3000

Barriles de salmón. .................2

Cajas de jerez....................

Toneladas de balastro ............... 100

Libras de hortalizas. . . . . . . . . . . . 1000

Barriles de agua.................... 944

El Glensannox llegó a Puntarenas el 30 de enero de 1873. El Inspector del Puerto certificó que 653 trabajadores chinos llegaban en ese barco desde Macao, en compañía de 54 miembros de la tripulación, incluidos el Capitán Dominico Capello, un médico y un intérprete. Además, el vapor italiano portaba 1351 piezas de carga consignadas a nombre de Carlos $\mathrm{H}$. Beavers $^{46}$.

Una semana después, en un artículo del Panama Star and Herald se informaba de que el vapor Glensannox procedente de China había arribado a Punta Arenas el 30 de enero con 654 chinos, y se señalaba que 31 personas habían fallecido durante el viaje ${ }^{47}$. El Star indicaba

"Exports", en: Pacific Commercial Advertiser. Ibíd., p. 2.

Costa Rica. Gaceta Oficial, 5 de febrero de 1873, citado en: Carlos Meléndez y Quince Duncan. El Negro en Costa Rica. San José: Editorial Costa Rica, 1972, p. 62. Ver también, Secretaría de Fomento, Documento nro. 1055, Sección Historia, Archivo Nacional de Costa Rica, citado en: Casey Gaspar, Jeffrey. "La inmigración china", en: Revista de Historia, Universidad Nacional, Escuela de Historia, Heredia, Costa Rica, Año I, nro. 1, p 175.

Panama Star and Herald, 8 de febrero de 1873, nro. 3718, p. 2. Nota: Esta referencia enlista un chino adicional, en contraste con el informe del Inspector del Puerto de Puntarenas, quien muy probablemente contó con la ventaja de haber examinado directamente a las personas y los documentos. también que el señor Hübbe, quien había actuado como agente del gobierno de Costa Rica en las gestiones para traer a aquellos trabajadores, había vuelto a Puntarenas desde Hong Kong para esperar la llegada del vapor ${ }^{48}$. No se hace mención de la presencia del representante del gobierno italiano, como se esperaba. La correspondencia diplomática entre G. Anfora, Chargé d'Affaires de Italia en Centroamérica, con residencia en Guatemala, y el doctor Lorenzo Montúfar, Ministro de Relaciones Exteriores de Costa Rica, sugiere que W.C. Riotte, Cónsul de Estados Unidos en Costa Rica, actuó como Cónsul ad interin de Italia en Costa Rica antes de que O. Hübbe fuera designado Cónsul de Italia en Costa Rica a partir del 3 de noviembre de 1873. Una lista de los cuerpos diplomático y consular acreditados en Costa Rica muestra que el señor. Hübbe sirvió como Cónsul italiano en Costa Rica, con residencia en San José, hasta $1880^{49}$. No hay duda de que esta designación tuvo como fin cumplir con las regulaciones de Macao en el sentido de que los chinos contratados para trabajar en ultramar debían contar con un funcionario consular que les sirviera como representante $y$ protector.

En este aspecto, la llegada de los chinos traídos desde Macao, entonces territorio

\section{Ibíd., pp. 653-654.}

49 Costa Rica. En: "Memorias presentadas al Congreso Constitucional de la República de Costa Rica en su período ordinario (1875-1880)". Por los secretarios de estado en los Despachos de Relaciones Exteriores, Instrucción Pública, Culto, y Beneficencia. (Listas) Cuerpo Diplomático y Consular Extranjero Acreditado en Costa-Rica, 1875, 1876, 1877, 1878, 1879, 1880. Ver también, Guatemala, 6 de diciembre de 1873, G. Anfora de Linganno, Encargado de Negocios, Legación de Italia en Guatemala, al Ilustrísimo Ministro de Relaciones Exteriores, San José de Costa Rica, 6 de Diciembre de 1873, en: Dirección General del Archivo Nacional, Departamento Archivo Histórico, San José de Costa Rica; 20 de enero de 1874, carta de O. Hübbe al Honorable Señor Ministro de Relaciones Exteriores de Costa Rica. Nombramiento de su Majestad el Rey de Italia para Cónsul del Reino de Italia (en Costa Rica) En: Dirección General del Archivo Nacional de Costa Rica, Departamento Archivo Histórico, Fondo Relaciones Exteriores, Caja nro. 61, enero 20, 1874. 
portugués, condujo a una ampliación de las relaciones diplomáticas de Costa Rica con Italia y Portugal. En su informe de 1873, el doctor Lorenzo Montúfar, Ministro de Relaciones Exteriores, informaba al Congreso de la República que don Adolfo Cristian, Conde de Lindemann, Ministro Plenipotenciario de Costa Rica ante el Reino de Italia, se encontraba negociando un Tratado de Amistad, Comercio, Navegación, Relaciones Consulares y Extradición con el gobierno italiano. El Ministro Montúfar señalaba, además, que se cultivaban relaciones amistosas con el gobierno de Portugal, y citaba el hecho de que las autoridades portuguesas de Macao habían aprobado la emigración de chinos a Costa Rica. Como respuesta, el gobierno de Costa Rica había dirigido las apropiadas muestras de gratitud al Ministerio de Relaciones Exteriores de Portugal ${ }^{50}$.

En conclusión, la entrada de los chinos procedentes de Macao es un acontecimiento que se convertiría en parte importante de los anales de la historia y la cultura de la nación costarricense. En Macao, algunos de los funcionarios que llegaron a aprender nombres $y$ lugares del pequeño y poco conocido país de Costa Rica se vieron más tarde involucrados en diversos aspectos de las relaciones entre Macao, Portugal y diversos países americanos. Aún más, debemos tener en cuenta que poco después de la llegada del Glensannox a Puntarenas se produjeron hechos que cambiarían la historia de Macao. Menos de un año después de la llegada de los chinos contratados por el señor Hübbe para trabajar en Costa Rica, el movimiento para introducir en las Américas trabajadores chinos contratados en Macao fue detenido.

El 20 de diciembre de 1873, João de Andrade Corvo, Ministro de Relaciones Exteriores y Secretario de Estado para los Asuntos de Ultramar de Portugal, emitió un decreto ministerial que ordenaba el fin de la emigración, desde Macao, de trabajadores

Informe presentado al Congreso Constitucional de la República de Costa Rica por el doctor Lorenzo Montúfar, Secretario de Relaciones Exteriores, Instrucción Pública, Culto y Beneficencia, San José, 1873, Costa Rica: Imprenta Nacional, pp. 13-15. chinos $^{51}$. Andrade Corvo remitió este decreto al Gobernador S. Januário y le informó que $\mathrm{Su}$ Majestad el Rey de Portugal había llegado a aquella conclusión después de revisar numerosos documentos relativos a la emigración de coolíes chinos que habían sido exportados como trabajadores contratados desde China hasta países extranjeros. El Rey declaraba que ya no era posible evitar los abusos cometidos con motivo de aquella emigración, pese a las detalladas regulaciones y la escrupulosa vigilancia ejercidas por las autoridades portuguesas en Macao ${ }^{52}$. Consecuentemente, el 27 de diciembre de 1873 el Gobernador S. Januário emitió la Portaria (decreto) nro. 89 que establecía el 27 de marzo de 1874 como la fecha en que terminaría la emigración. Su texto se leía como sigue:

Nro. 89. El Gobernador de la provincia de Macao y Timor y sus dependencias...:

Por orden del gobierno de Su Majestad,... se ha decidido lo siguiente:

Queda prohibida la emigración china por el puerto de Macao.

En conformidad con el artículo nro. 83 de la regulación que se ha aplicado a la emigración de chinos, la orden será implementada tres meses después de la presente publicación (27 de marzo de 1874).

Portaria emitida por el Ministerio de Marina y Ultramar, al Gobernador da la Provincia de Macao y Timor, el 20 de diciembre de 1873, acabando con la emigración de personas chinas contratadas en Macao. 20 de diciembre de 1873 B. João de Andrade Corvo, en: Relatorio y Documentos Sobre la Abolición de la Emigración de Chinos Contratados en Macau, presentado a las Cortes, Sesión Legislativa de 1874. Por el Ministro y Secretario de Estado de los Negocios de la Marina $y$ de Ultramar (Andrade Corvo) Lisboa: Imprenta Nacional, 1874, p.138. 
Las autoridades responsables de la ejecución de esta ley, entienden que deben seguirla.

Palacio de Gobierno de Macao, 27 de diciembre de 1873.

(Firma) El Gobernador de la Provincia y Ministro Plenipotenciario de Su Majestad ante China, Japón y Siam, Vizconde de San Januário ${ }^{53}$.

Poco después, el Gobernador S. Januário le escribió al Ministro Andrade Corvo informándole que tras la publicación de la Portaria nro. 89 del 27 de diciembre de 1873, su oficina se había abocado a otras consideraciones. La supresión del tráfico de trabajadores contratados no era su única preocupación. Alguna compensación debería ser asignada a los numerosos empleados que perderían la mayor parte de sus ingresos $y$, adicionalmente, muchos chinos que actuaban como intermediarios de la emigración, bajo contrato con los agentes procuradores de mano de obra, también habían perdido sus empleos. Deberían abrirse nuevos horizontes al comercio desde Macao y el Gobernador informaba que estaba estudiando la posibilidad de implantar nuevas regulaciones aplicables a los viajes individuales de chinos hacia países extranjeros, similares a las que se habían adoptado en Hong Kong. Finalmente, el Gobernador S. Januário recordó que en un previo intercambio epistolar con el Ministro Andrade Corvo él había mostrado preocupación en torno a la considerable disminución de ingresos que podría darse en Macao, dado que muchos individuos serían afectados. Habría una crisis, pero él creía que esta sería temporal y el equilibrio fiscal de Macao sería nuevamente restablecido. Las personas afectadas deberían dedicarse paulatinamente a otras ocupaciones y el fisco debería asegurarse nuevas fuentes de ingreso. Concluía

Portaria Nro. 89 expedida por el Gobernador de la provincia de Macao y Timor... y Ministro Plenipotenciario de Su Majestad... Vizconde de S. Januário, Palacio del Gobierno de Macao, 27 de diciembre de 1873. En: Boletim da Provincia de Macau e Timor, 27 dezembro, 1873. enfatizando que la nueva legislación liberaría a Portugal de muchas acusaciones, $y$ asegurándole al Ministro que, mientras continuara en su posición, haría todo lo posible por ser de utilidad en una transición que presentaba muchas dificultades. Solicitaba su ayuda en la forma de autorización para emitir los estatutos que fueran necesarios, ya que él, en calidad de Gobernador, no poseía el poder de aprobarlos ${ }^{54}$.

Al tiempo que Macao entraba en una nueva fase en la historia de la migración hacia Latinoamérica, los chinos traídos a Costa Rica en el Glensannox se convirtieron en parte del mosaico de culturas de la Costa Rica del siglo XIX. Fue un caso "único", pero se convirtió en parte de memoria histórica, tanto de las Américas como de Macao.

\section{BIBLIOGRAFÍA}

\section{LIBROS Y REVISTAS}

Andrade Corvo, João. Relatorio y documentos sobre la abolición de la emigración de chinos contratados en Macau. Lisboa. Imprenta Nacional, 1874: 138-139.

Basto da Silva, Beatriz. Emigração de Cules dossier Macau 1851-1894. Macau. Fundação Oriente, 1994: 143.

Casey Caspar, Jeffrey. "El ferrocarril al Atlántico en Costa Rica 1871-1874". Anuario de Estudios Centroamericanos, 1976: 291344.

"La inmigración china". Revista de Historia 1. Heredia. Universidad Nacional, Escuela de Historia, 1975: 145-165, 175.

Carta del señor Vizconde de S. Januário, Gobernador de la Provincia de Macao y Timor, al señor Ministro y Secretario de Estado de los Negocios de la Marina y de Ultramar. Palacio del Gobierno de Macao, 3 de enero de 1874, en: Relatorio y Documentos sobre la Abolición de Chinos Contratados en Macao. Presentado ante las Cortes en la Sesión Legislativa de 1874, pp. 138-139. 
Costa Rica. "Memorias presentadas al Congreso Constitucional de la República de Costa Rica en su período ordinario 1875-1880". Por los Secretarios de Estado en los Despachos de Relaciones Exteriores, Instrucción Pública, Culto y Beneficencia. Listas Cuerpo Diplomático y Consular Acreditado en Costa Rica, 1875, 1876, 1877, 1878, 1879, 1880.

de Castro Sampaio, Manuel. "Os Chinos em Macau”. Hong Kong: Typographia de Noronha e Filhos, 1867.

Fonseca Herrera, Zaida María. "Los chinos en Costa Rica en el siglo XIX". [Tesis de grado]. Escuela de Historia $y$ Geografía, Facultad de Ciencias Sociales. Universidad de Costa Rica. San José, 1979.

Forjaz, Jorge. Familias Macaenses II. Macau. Fundação Oriente: Instituto Cultural de Macao. Lisboa. Instituto Portugués del Oriente, 1996: 646-657.

Hatch, John Keith. Minor C. Keith. Pioneer of the American Tropics. Virginia: Mc Lean, 1962.

Herrera Balharry, Eugenio. Los alemanes, y el Estado cafetalero. San José: Editorial Universidad Estatal a Distancia, 1988.

Leopold, Werner F. Der Deutsche in Costa Rica, p. 86 .

Meléndez Chaverri, Carlos y Duncan, Quince. El negro en Costa Rica. San José: Editorial Costa Rica, 1972.

Montalto de Jesus, C.A. Macau Histórico. (1926. Primera edición portuguesa, traducida del inglés original, Historic Macao, por María Alice Morais Jorge). Macau. Livros do Oriente, 1990: 271-277.
Montúfar, Lorenzo. "Informe presentado al Congreso Constitucional de la República de Costa Rica”. Costa Rica. Imprenta Nacional. 1873: 13-15.

Murillo Chaverri, Carmen. Identidades de hierro y humo. La construcción del ferrocarril al Atlántico 1870-1890. San José: Editorial Porvenir, 1995.

Pérez de la Riva, Juan. El Barracón y otros ensayos. La Habana: Editorial de Ciencias Sociales. Instituto Cubano del Libro, 1975.

Soto Quirós, Ronaldo. "Inmigración e identidad nacional. 1904-1942”. [Tesis para optar por el grado de Licenciatura en Historia]. San José. Universidad de Costa Rica: Facultad de Ciencias Sociales, Escuela de Historia. 1998: 258-328.

Soley Güell, Tomás. Historia económica y hacendaria de Costa Rica 1. Tomo 1. San José. Editorial Universitaria, Sección Ciencias Sociales y Jurídicas. 1947: 296 303.

Stewart, Watt. Chinese Bondage in Perú. A History of the Chinese Coolies in Perú, 1849-1874. Durham: Duke University Press, 1951.

Keith and Costa Rica. A Biographical Study of Minor Cooper Keith, Albuquerque: The University of New Mexico Press, 1964.

Tanco Armero, Nicolás. Viaje de Nueva Granada a China y de China a Francia. (con una Introducción por Pedro María Moure). Perú: Imprenta de Simon Raçon y Comp., 1861.

Teixeira, Manuel. O Comércio de Esclavos em Macau. The So Called Portuguese 
Slave Trade in Macau. Macau: Imprensa Nacional. 1976.

"Visconde de S. Januário". A Medicina em Macau I. Asistencia Médica em Macau. Macau: Imprensa Nacional, 1976: 79-99.

\section{PERIÓDICOS}

Boletim da Provincia de Macau e Timor. 23-111872: 206.

Boletim da Provincia de Macau e Timor. 27-121873.

El Heraldo. Antioquia, Colombia, 1-4-1869: 87.

Hawaiian Gazette. 1-1-1873: 3.

Hong Kong Daily Press. 12-11-1872: 2.

Pacific Commercial Advertiser. Honolulu, 30-11-1872: 5.

Pacific Commercial Advertiser. Honolulu, 21-12-1872: 2.

Pacific Commercial Advertiser. Honolulu, 28-12-1872: 2-3.

Panama Star and Herald. 8-2-1873: 2.

DOCUMENTOS

Archivo Histórico Nacional. Madrid. Sección Ultramar. Legajo 86. Carpeta 4. Expediente 38.
Archivo Nacional de Costa Rica. 9420. Judicial, San José. Juzgado Segundo Civil.

. Dirección General del Archivo Nacional de Costa Rica. Departamento Archivo Histórico, 6 de diciembre, 1873.

. Dirección General del Archivo Nacional de Costa Rica, 1874. Departamento Archivo Histórico, Fondo Relaciones Exteriores. Caja 61, enero 20.

Arquivo Geral da Marinha. Lisboa. 1872. Macao. Nucleo 916, Caixa 4, Correspondencia Recebida e Expedida, 19 de Outubro.

Arquivo Histórico de Macau, Marinha. Lisboa. 1872. Nucleo 916, Caixa 4, Processo 1872. nro. 758, 21 de Outubro.

Lisboa. 1872. Nucleo 916, Caixa 4, Oficios Expedidos, 22 de Outubro.

. Lisboa. 1872. Nucleo 916, Caixa 4, Correspondencia Recebida/Expedida 1870-1872, nro. 443, 6 de Novembre.

Lisboa. 1872. Nucleo 916, Caixa 4, Superintendencia de Emigração Chineza, 8 de Novembre.

Lisboa. 1872. Nucleo 916, Caixa 4, Correspondencia Recebida e Expedida, 1870-1872, 16 de Novembre.

Arquivo Histórico Ultramarino. Lisboa. 1872. Caixa 43, nro. 208. Macao, 12 de Novembre. 
